\title{
CORRECTION
}

\section{Correction to: An overview of chiral separations of pharmaceutically active substances by HPLC (2018-2020)}

\section{Sofiya Grybinik ${ }^{1}$ Zuzana Bosakova ${ }^{1}$}

Published online: 14 September 2021

๑) Springer-Verlag GmbH Austria, part of Springer Nature 2021

\section{Correction to: \\ Monatshefte für Chemie - Chemical Monthly (2021) 152:1033-1043 \\ https://doi.org/10.1007/s00706-021-02832-5}

In the original publication, reference citation 4 was incorrectly added to the following text under first paragraph of Introduction section. The text reads as "During this research it was discussed that $S$-chloroquine and $S$-hydrochloroquine could potentially have a higher response against SARS$\mathrm{CoV}-2$ than their enantiomers thus putting to the fore the necessity of chiral separation [4]."

The correct sentence should read as follows:
The original article can be found online at https://doi.org/10.1007/ s00706-021-02832-5.

Zuzana Bosakova

bosakova@natur.cuni.cz

1 Department of Analytical Chemistry, Faculty of Science, Charles University, Albertov 2038, Prague, 128 00,

Czech Republic
During this research it was discussed that $S$-chloroquine and $S$-hydrochloroquine could potentially have a higher response against SARS-CoV-2 than their enantiomers thus putting to the fore the necessity of chiral separation.

Publisher's Note Springer Nature remains neutral with regard to jurisdictional claims in published maps and institutional affiliations. 